\title{
EJIL:Talk!
}

Blog of the European Journal of International Law

October 24, 2019

\section{UNCITRAL and ISDS Reform: Visualising a Flexible Framework}

Written by Anthea Roberts and Taylor St. John

Share

Tweet

Email

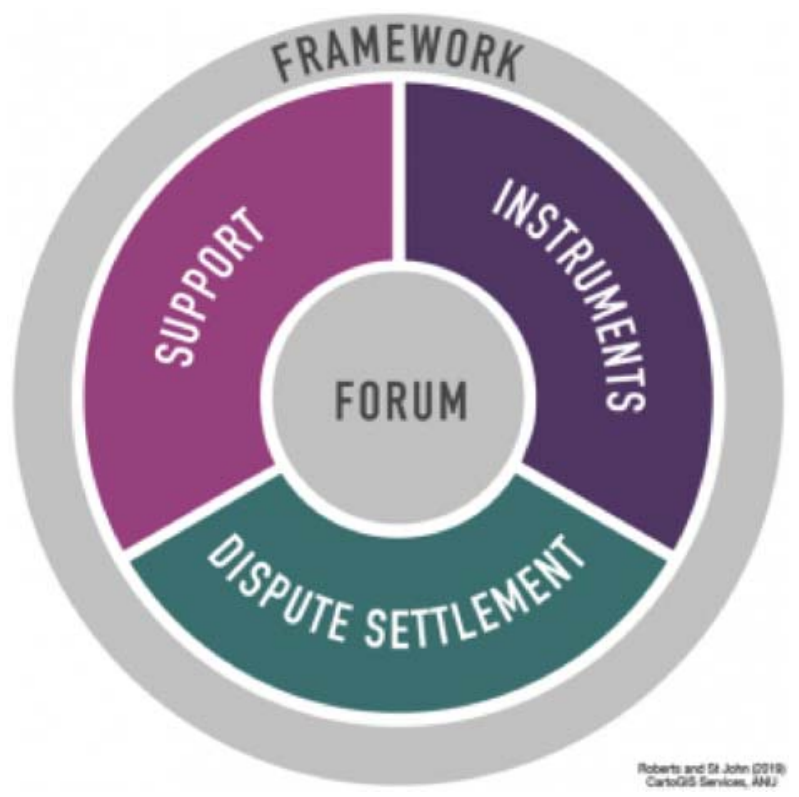

In UNCITRAL, states have broken through the impasse of the incrementalist and systemic reformer camps. They have all agreed that they want to pursue systemic reform, but they have different ideas about what that entails and what to prioritise. In broad terms, agreement seems to be coalescing around three main blocks of reforms: updating some of the procedural rules; enacting some sort of optional structural changes for dispute settlement; and creating a mechanism to support developing states with handling their treaties and disputes. Not every state is supportive of every proposal, but most seem open to pursuing all three in a (somewhat) simultaneous fashion.

That leaves an important question, which is starting to bubble up on the side lines of the negotiations: how might these different reforms fit together? Instead of treating the proposals as oppositional, could a flexible framework be developed that would allow multiple reforms to 


\section{EJIL:Talk!}

Blog of the European Journal of International Law

In this blog series, we typically provide analytical frameworks for (1) understanding how the process is unfolding, including the politics of different camps and the sociology of different actors, and (2) predicting how the process is likely to evolve. In this blog, we are doing something a bit different. We are taking concerns that states have identified in the process and sketching a framework for understanding how they might be brought together. The framework we present below is not simply a descriptive synthesis of the discussions to date, but rather a way to look at the various options raised in their entirety - including how they overlap and relate to one another.

We are not predicting that this is what states will do; that is a choice for the states. However, like the state delegations, we have been searching for a conceptual framework to guide our thinking and sometimes a picture tells a thousand words. So, here are our initial thoughts on how to visualise a flexible framework for ISDS reform and how these more centralised reforms might operate within the wider more decentralised field. We welcome feedback from all actors on this conceptualisation and are open to revising and refining it.

\section{Framework}

We start with the observation by Chile, Israel, Japan, Mexico and Peru that the Working Group should develop a suite of reforms while giving states 'maximum flexibility' to allow states to 'choose and adopt the best solution based on their specific needs and interests.' However, while they focus on procedural reforms, we expand their suggestion to create a flexible framework into which all the types of reform under discussion can be docked and developed in a separate but integrated fashion. The Working Group has repeatedly stressed that states should be given the choice about what options they ultimately select. Therefore, choice or flexibility is fundamental: here we present an overall framework with the idea that individual states can pick and mix individual reforms.

This framework could be created in several different ways. In Vienna, states typically referenced two models: the Mauritius Convention and the OECD's Multilateral Convention to Implement Tax Treaty Related Measures to Prevent Base Erosion and Profit Sharing (MLI). The 


\section{EJIL:Talk!}

Blog of the European Journal of International Law

feasible way forward. Although both models are mentioned positively in the submissions of Chile, Israel, and Japan; Colombia; Ecuador; the European Union; and recent academic work, here we draw on Colombia's submission, which explains the MLI and how it could apply in investment.

As Colombia notes, the novelty of the MLI is the flexibility it grants to parties. It allows each party to specify the tax treaties to which the Convention will apply. When two parties specify a mutual treaty, a 'match' occurs, and a new layer of rules then applies to that treaty. In this regard, the MLI is similar to the Mauritius Convention. The MLI has an additional feature that may prove useful: it enables states to opt-in block-by-block or piece-by-piece, rather than signing or not signing the entire Convention. This feature means that there can be matches between and within particular blocks of rules. If two states sign onto the framework and both opt for updating the procedural rules while only one accepts structural reforms, only the former would apply between them. Within the block of procedural reforms, if both end up accepting the code of conduct, but only one opts for a limitation on damages, only the former would apply to arbitrations under their treaties.

There could even be sub-matches: for instance, some states may choose strict regulation of third-party funding while other states choose disclosure only. In these topics, states may wish to define minimum standards or obligations, another feature of the MLI model. Minimum standards could provide useful additional flexibility for states on topics where their preferred reform options vary, but it is possible to agree on a common baseline.

\section{Forum}

We have placed a forum at the centre of the framework for a reason. As a radically decentralised system, states have never had a common hub in which they come together and talk about the system as a whole what is working and what is not, what reforms should be considered, what negotiations might need to happen next, and what interpretive declarations should be adopted. Yet, as noted in our last blog, states waking up to the importance of a shared forum may be the most 


\section{EJIL:Talk!}

Blog of the European Journal of International Law

Through the UNCITRAL process, states are growing accustomed to regular meetings at a centralised hub, which enables plenary discussions and side conversations that prompt them to focus on their roles as the principals of the system and how they might exert better oversight, both collectively and individually, over their treaties and obligations. In other words, we see these conversations as a step toward more action, inside and outside of UNCITRAL; there seems to be energy to keep meeting, to keep learning, and to keep reforming and we doubt that states will turn the tap off on this anytime soon. This energy from the UNCITRAL process is why we have put a permanent hub for deliberation or negotiation at the centre of the framework.

The UN Framework Convention on Climate Change might provide a good model. The UNFCCC is an umbrella, framework agreement that enjoys broad legitimacy because of its near universal membership (197 parties) and it creates a docking station for developing more specific agreements with more limited membership. The parties meet annually as a Conference of Parties to assess progress in dealing with climate change and can respond to new challenges as they arise. The meetings of the Conference of Parties have then become the staging ground for negotiating other reforms, like the Kyoto Protocol. The Meetings of the Parties of the Kyoto Protocol also meet during the Framework Conferences. Parties to the Convention that are not parties to the Protocol can observe Protocol-related meetings, but they play no role in the governance of the Protocol.

Something similar could be envisaged in the investment context that would provide a framework on investment policy more broadly, not just investment protection or dispute settlement. Each part of the flexible framework would have a different (though overlapping) set of treaty parties, though there would likely be a core group of states that are signed up to all or most parts. Thus, although the centre shows a general forum, the collective principals for each reform option will differ based on the membership of that particular part. States that have opted-in to a particular part of the treaty would then be the collective principal for that aspect of the framework. For instance, the collective principal for an appellate mechanism would comprise the states that are members of 


\section{EJIL:Talk!}

Blog of the European Journal of International Law

The image below shows our framework in more detail. We have depicted the central forum using overlapping Venn diagrams. For stylised purposes, we have started by using equally sized circles to which treaty parties for a particular part of the framework can be added. Of course, some parts of the framework are likely to have larger memberships than others, and the degree of crossover among different parts will change over time. Some aspects could be deemed 'core' or 'minimum standards' initially or later, if states wished, making them non-optional along with other parts that are opt-in. It is also possible that states could choose to nest some components, such as an optional court of first instance, within others, such as an appellate mechanism. We have models for this from other areas. For instance, the World Bank Group, which has five parts, each with different memberships, holds one set of Annual Meetings, during which each state attends the meetings for the parts it has joined. We depict this dynamism in the smaller images at the end of this blog, which show how the collective principals within the forum shift depending on the subject matter.

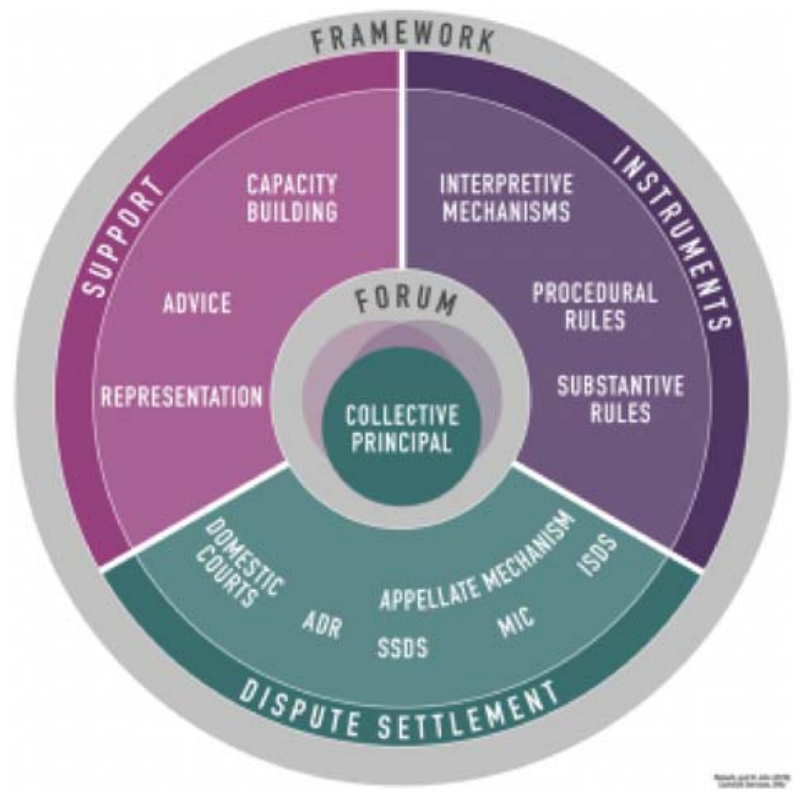

3. Instrumrents, Blspute Settlemrent and Šupport

To us, the types of reform that states are discussing seem to fit broadly under three headings: instruments, dispute settlement, and support. We unpack what reforms fit under each heading to a degree here, but the exact contours of the reforms under each element will likely evolve over time. 


\section{EJIL:Talk!}

Blog of the European Journal of International Law

By interpretive mechanisms, we refer to instruments that enable states to adopt binding interpretations of their treaty obligations, which provide guidance to dispute settlement tribunals. In Vienna, several states mentioned interpretive committees in their recent treaty practice. As the EU set out in its submission, it might be important to create interpretive committees for older-style treaties that lack them and it would be good to have a place in which parties to a bilateral agreement could meet in order to 'retain control over the interpretation of their agreement by being able to adopt binding interpretation.' Therefore, we envision the 'interpretive mechanisms' space to be populated by multiple mechanisms: interpretive committees created by recent treaties, bilateral treaty partners who wish to issue a joint interpretation, or plurilateral opt-in interpretative statements.

Next we have procedural rules. Several states, including Australia and Peru, suggested the possibility of a multilateral instrument on procedural reforms in Vienna. We see this space in the figure as the home for codes of conduct, rules on third party funding, and other multilateral procedural rules generated by Working Group III. Procedural rules developed in other places could also be brought into this framework if states wished; for instance, preparatory work being done at the OECD on reflective loss could imported here as could some or all of the revised ICSID Rules. Heeding the calls of many states to avoid duplication, it may make sense to let groups of interested states, and interested institutions, spearhead the development of particular reform efforts. These efforts could be brought back into Working Group III or into a future forum and discussed in plenary before being docked into the framework for optional sign-on.

The third component within instruments is substantive rules. Although the initial mandate of Working Group III focuses on procedural rules, this procedure-substance division may be dissipating somewhat over time. Signs of this dissipation include Indonesia's submission noting that 'procedural law is inherently substantive and vice versa' or Thailand's observation that 'substantive and procedural aspects of the ISDS system are often closely intertwined, and reforms in both areas can go 


\section{EJIL:Talk!}

Blog of the European Journal of International Law

substance and are already on the Working Group's agenda. South Africa's submission and NGO submissions also call for consideration of substantive reforms. Other subtler signs of the dividing line fading somewhat include comments by actors in Vienna, like the European Union, that one of 'the problem[s] we face is the stock of existing treaties.' On substantive rules, Working Group III may wish to coordinate with or import work being done at UNCTAD, especially on revising the stock of existing treaties.

Second, we would have reforms concerning dispute settlement options. Here, we have listed multiple options, reflecting the various preferences of states. We start with domestic courts given that some states, like South Africa, are advocating using them to resolve investment disputes and others are seeking new rules on things like exhaustion of local remedies. Then we have alternative dispute resolution (ADR); we envision ADR broadly, to include all nonadjudicatory means of dispute prevention and settlement. This includes ombudsmen to help prevent and resolve disputes, mentioned in Brazil, Korea, and South Africa's submissions. It also includes conciliation and mediation, which many states mention in their submissions, including China, European Union, Mali, and others. We also note the trend, for instance in Brazil's treaties, toward thinking about all phases of investor-state interaction collectively, from promotion and facilitation onward to dispute settlement, and think these considerations could fit here. Next we move to state-state dispute settlement (SSDS) mentioned in Brazil and South Africa's submissions, and also the European Union's where they envision making an appellate mechanism potentially open to investor-state and state-to-state disputes.

Then we move to a standing mechanism, including both a court of first instance and an appellate tribunal. The appellate tribunal floats above both the court and ISDS in our image; this is to illustrate the open architecture approach we put forward that was subsequently picked up by the European Union. In an open architecture approach, an appellate tribunal can hear cases appealed from arbitration or from a court of first instance. For instance, China's submission suggests that it may opt into an appellate tribunal and keep ISDS, which could be compatible with the EU option for a court of first instance and an appellate mechanism, if an 


\section{EJIL:Talk!}

Blog of the European Journal of International Law

One of the aims of depicting the dispute settlement options in this way is to create a framework for states thinking about what the different options are and how they should be linked. For instance, on a general level, would an appellate mechanism be able to take cases from an investment court, ISDS and state-to-state disputes? Should access to ISDS or an investment court be made contingent on the exhaustion of local remedies or prior resort to consultations, conciliation, or mediation? Once states have agreed upon general rules about how links between these options might be structured, individual states could make their own choices about which options they want to adopt.

Third, we have support mechanisms. There was a lot of discussion this time around about how best to support developing states to manage their treaties and disputes, as we detailed in the last blog. We have included here capacity building for states, advice and representation as key potential functions that a support mechanism could provide. In many ways, the UNCITRAL forum is already starting to function as a nascent support mechanism and it might make sense to develop the capacity-building element of this mechanism during the negotiations in order to assist states in navigating these reforms. After all, as Gabon reflected in Vienna, if states have a tool but cannot use it effectively, it is like they never had the tool in the first place.

\section{Balanelng Eentrallsation and Becentralisation}

Any international regime must balance the pros and cons of centralisation and decentralisation. Centralisation may bring about greater consistency and efficiency, but might stifle innovation and make the system brittle and not resilient in the face of changing circumstances. Decentralisation may bring about greater dynamism and room for individual preferences, but it may foster inconsistency and make it harder to find ways to provide efficient solutions to widespread problems. System designers want efficiency and resilience, but often these two goals pull in different directions and the key is to find some balance between the two.

Interestingly, the balance between centralisation and decentralisation is shifting in both the trade and investment regimes. Previously the 


\section{EJIL:Talk!}

Blog of the European Journal of International Law

agreements, but also toward greater room for plurilateral agreements and dispute resolution mechanisms in the WTO. In investment, we see attempts to work out how to retrofit certain more centralising roles and institutions onto a decentralised system. It seems unlikely that reforms like an appellate mechanism or investment court would replace ISDS in total. Instead, we are likely to see a more fluid and plural coexistence of more centralised and decentralised options.

In outlining this vision of a more holistic framework for ISDS reforms, we are not starting from scratch nor are we trying to create a perfect single model. Instead, we are working with a well-developed, existing, decentralised landscape onto which we are trying to graft a flexible framework that permits dynamism and experimentation, enables common agreement but creates room for difference.

This framework does not remove contestation. On the contrary, we expect states to have vigorous disagreements on a macro level (e.g., about what reforms to pursue and in which order) and a micro level (e.g., about how to formulate particular procedural rules, whether to reform any of the substantive rules, and how to structure an open architecture permanent mechanism). We expect various international organisations to jostle over which one takes the lead on what, and different practitioners, NGOs and academics to contest whether the system is legitimate or illegitimate and whether the proposed reforms go too far or not far enough.

In the end, as masters of their treaties, states have the power to decide collectively what reforms to pursue, in what order and in what form. Individually, they will also have choice about which particular reform options to adopt. We offer this flexible framework as one way of conceptualising the choices that states are currently trying to navigate. But the choice in these issues ultimately lies with states in what is clearly, and deliberately, a government-led process. 


\section{EJIL:Talk!}

Blog of the European Journal of International Law
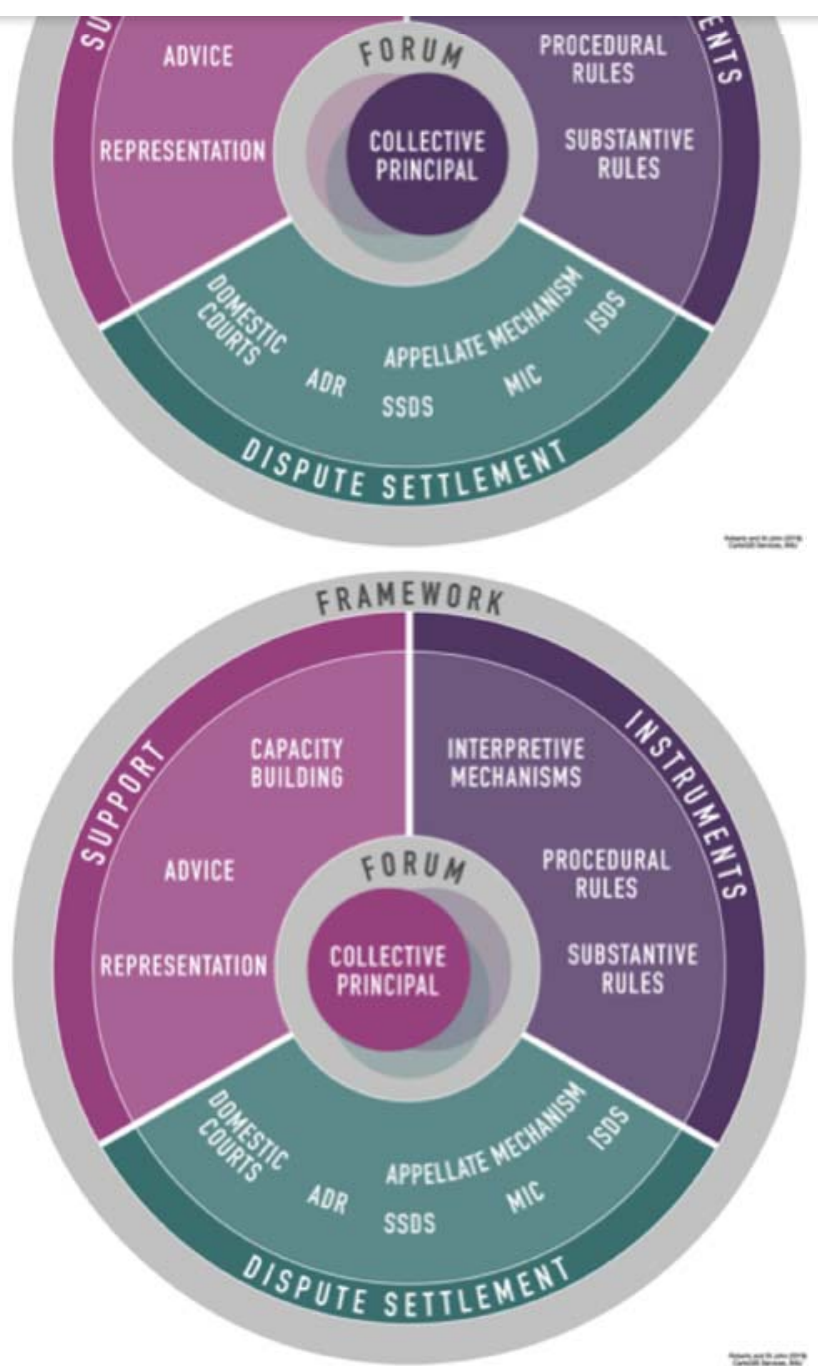

Note: We would like to thank Karina Pelling at CartoGIS, ANU for helping us to develop these visualisations.

\section{Related}

UNCITRAL and ISDS

Reforms: Hastening slowly

April 29, 2019

In "Bilateral Investment

Treaties"
UNCITRAL and ISDS

Reforms: Agenda-

Widening and Paradigm-

Shifting

September 20, 2019

In "Bilateral Investment

Treaties"
UNCITRAL and ISDS

Reform: Pluralism and the

Plurilateral Investment

Court

Desember 122017

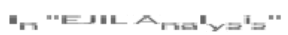

\section{CATEGORIES}




\section{EJIL:Talk!}

Blog of the European Journal of International Law

UNCITRAL

UNCITRAL ISDS

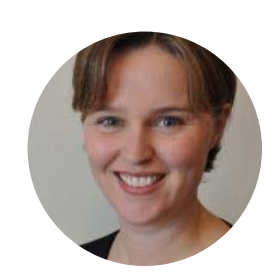

\section{Anthea Roberts}

Anthea Roberts is a Professor at School of Regulation and Global Governance (RegNet) at the Australian National University and a Visiting Professor for the Masters of International Dispute Settlement...

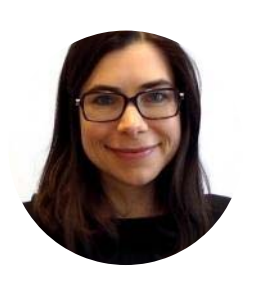

\section{Taylor St. John}

Taylor St John is a Lecturer in International Relations, University of St Andrews, and a Senior Research Associate at the Global Economic Governance Programme, University of Oxford. Her monograph, The...

\section{LEAVE A COMMENT}

